\title{
Detecting Gifted Students at Age 7 to 17 Years With Attention Deficit Hyperactivity Disorder in the Kingdom of Saudi Arabia
}

\author{
Rahma Alzahrani, Abdulhamid Alarfaj, Tareq Melhem \\ Special Education, King Faisal University, Saudi Arabia
}

\begin{abstract}
The research study investigates the effectiveness of using the Overexcitabilities Scale to detect gifted students with attention deficit hyperactivity disorder $(A D H D)$. The sample consisted of 36 males and females students, whose ages ranged between 7 to 16 years. They have divided into four groups: Student with Attention Deficit Hyperactivity Disorder and their number was 6 students, the gifted student with Attention Deficit Hyperactivity Disorder and their number was 4 students, and the control group which are normal, unaffected, and non-gifted student and their number were 10 students, and the gifted and unaffected student and their number wasl6 students. The study found that the use of Overexcitabilities Scale in detecting gifted student among children with attention deficit hyperactivity disorder is effective. The statistical analysis indicated that the sample of gifted student with hyperactive attention disorder are supersensitive or they have Overexcitability in Intellectual, Sensual, and Psychomotor respectively, while children with the disorder have Overexcitability in Psychomotor, Sensual, and Intellectual respectively. The practical implications of these results suggest that specialists and educators must focus on the type of Overexcitability of the student with $A D H D$ as specific predictors of giftedness. Furthermore, the study indicates that the Scale of Overexcitabilities is a measure of giftedness for this category.
\end{abstract}

\section{Introduction}

One of the most important challenges facing education in Saudi Arabia to achieve Vision 2030 is the provision of appropriate educational services and programs for special education categories (Ministry of Education), and the lack of standards that used in detecting gifted students with Twice or MultiExceptional led to the neglect and unrecognized of this category among the other gifted student categories who deserve support and care.

Studies indicate that attention deficit hyperactivity disorder is the most common developing disorder Mullet and Rinn [1]. Therefore, there is a great interest from psychologists and brain research in knowing what this disorder is, in addition to a huge interest from special education in this category.
Attention Deficit Hyperactivity Disorder (ADHD) is a neurodevelopmental disorder observed among children. ADHD is characterized by several patterns of inattention (IA) and hyperactive or impulsive behaviors (HI) [2]. We find, as teachers in classrooms, many challenges with these students. The most important and excessive problem is dealing with attention and hyperactivity or impulsive behaviors. Although, there are still questions about the validity of the diagnosis of ADHD in children who are classified as gifted, but this diagnosis is correct among them.

The challenges of diagnosing ADHD in gifted students have not yet been addressed. Specially, we find that there is a dearth of information on how to distinguish inattention, hyperactivity, or impulsivity behaviors in gifted students compared to others. As well as the lack of a measure to detect their giftedness. The aim of this study was to search for the possibility of using the Overexcitabilities Scale as a measure to detect their giftedness, identify them, and making this subject more clear by comparing groups of different students, taking into account the participation of nongifted and those with the disorder.

\section{Attention Deficit Hyperactivity Disorder ADHD Concept}

Attention Deficit Hyperactivity Disorder is one of the most common behavior disorders in childhood, and the American Society has called this disorder "attention deficit hyperactivity disorder." Although the majority of people and even many specialists still call it "attention deficit", which is the name it was called in 1980, this name has changed as a result of many research results and studies conducted on these disorders, which confirmed the existence of strong indicators Indicates the accompanying hyperactivity of this disorder. Therefore, many specialists use these two terms interchangeably or with the expression of one case, which is either: attention deficit alone, hyperactivity alone, or Attention Deficit with Hyperactivity. Also, these results indicated that impulsive behavior is associated with many cases of Attention Deficit with hyperactivity [2].

We also find in the Diagnostic and Statistical Manual of Mental Disorders DSM-IV (2000) that eighteen of the total symptoms of the disorder were 
included under two separate groups nine symptoms for each group, which are the intentional behaviors (IA) such as distraction, and difficulty in focusing on tasks for a sustained period, and hyperactive behaviors or Impulsivity (HI) such as restlessness, excessive speech, and anxiety. This confirms the existence of three types of ADHD: (1) Attention Deficit Disorder only when there are at least six intentional behaviors. (2) ADHD when at least there are six hyperactive or impulsive behaviors. (3) ADHD when there are at least six intentional and six hyperactive or impulsive behaviors [3].

\section{Giftedness}

Sternberg's theory allows us to think of the needs of children with ADHD to demonstrate exceptional abilities or competencies in one or more scopes, although there is no universally accepted definition of giftedness. According to the National Association of Gifted Children, scopes refer to "any organized field of activity that has its own symbol system (such as mathematics, music, language) or a set of sensory skills (such as painting, dance, and sports)" [4].

According to Besnoy [5] regardless of the disorder, each one has distinct characteristics that must be addressed by teachers, parents, and school administrators.

Giftedness is defined in this research as high intelligence. In gifted students with Attention Deficit Hyperactivity Disorder, the students' scores obtained by the diagnosis of psychiatrists were viewed as being higher than 125 on the "Binet Scale" and their ages ranged from (7-10) years and the Student with Attention Deficit Hyperactivity Disorder were less than 120 .

The control group consists of normal students, academic achievement and the choice of teachers were considered, while the gifted and unaffected group was classified according to the "Miqyas Mawhiba" scale and academic achievement.

\section{Giftedness and Attention Deficit Hyperactivity Disorder}

A comprehensive concept of giftedness with multiple criteria is adopted, although most experts agree that the distinguishing feature of giftedness is high intelligence. In our study, we adopt the procedural concept that states that (the gifted child is the one who has obtained more than 120 in the "Binet Scale" of intelligence for those with Twice or MultiExceptional - and the academic achievement is more than $99 \%$ in the middle school and classified as a gifted from "Miqyas Mawhiba" scale)

Attention deficit hyperactivity disorder (ADHD) is a neurodevelopmental disorder observed among children. ADHD is characterized by multiple patterns of inattention (IA) and hyperactive or impulsive (HI) behaviors according to the Diagnostic and Statistical Manual of Mental Disorders (DSM-5) [6].

In some circumstances, the gifted can lead to emotional, behavioral, and social problems. These problems have been explained in terms of Overexcitability described in Dabrowsky's theory of positive dissociation. In this theory, "Overexcitailitiesas" refers to the way an individual experience and respond to the world in terms of psychomotor, Intellectual, Imaginational, and Emotional domains. Dabrowski suggested that individuals who respond excessively to stimulation or over-excitable will be hyperactive, impulsive, and unaware, which are the primary symptoms of ADHD, and there is evidence for this relationship. Some scientists have suggested that the hyperactive and impulsive behaviors exhibited by gifted individuals were secondary behavior rather than pure indications of ADHD, and this led to the failure to diagnose ADHD among gifted children, although it is actually there, and the validity of the diagnosis of ADHD among gifted individuals has also been questioned [7].

\section{Overexcitability}

Dabrowsky defined it as a superior ability that appears in form of reactions to internal and external stimuli that the individual shows as a huge desire to learn, lively imagination, physical energy, possesses excessive sensitivity, and intensity of emotions. It appears in five superior psychological patterns which are Psychomotor, Sensual, Intellectual, Imaginational, and Emotional. These patterns consider as an indication of developmental potential and Giftedness. Each of these patterns can be defined as

\subsection{Psychomotor Overexcitability}

The Psychomotor Overexcitability can be expressed by increased physical energy, speed of speech, nervousness, impulsive decision-making, a sense of restlessness or continuance boredom, workaholism, hyperactivity, and inattention. Moreover, the most common symptoms of psychomotor in classrooms are talking quickly, pulling hair, licking lips, sucking fingers, chewing pens, and other behaviors.

\subsection{Sensual Overexcitability}

Sensual Overexcitability consists of reactions to sensory stimuli. Because of that individuals with sensual overexcitability show many artistic interests, such as acting, an increased need to touch things, and the response to natural surrounding stimuli such as noise and light. Sensual Overexcitability can be found inside the classroom in form of a huge interest in many 
stimuli such as fluorescent lights and smells at the expense of the academic aspect.

\subsection{Imaginational Overexcitability}

Imaginational Overexcitability indicates a person's ability to imagine things well. The hyper-imaginative individual is often characterized by the ability to associate imaginary images, impressions, frequent use of images, creativity, increased awareness, use of metaphors in verbal expression, mixing truth with fantasy, daydreaming, fear of the unknown, living in a fantasy world to escape from feeling bored.

\subsection{Intellectual Overexcitability}

Individuals with high Intellectual Overexcitability are characterized by having active minds, having a desire for more knowledge, curiosity, the ability to focus and theoretical thinking, and an interest in theoretical problems.

\subsection{Emotional Overexcitability}

Emotional Overexcitability is characterized by deep emotional capacity, emotional attachment, hypersensitivity to others, places, and things, sensitivity in relationships with others, and having compassion and empathy. They are also characterized as having a strong emotional memory and feel anxiety and fear of death and loneliness [8].

\section{Research Rationale}

The research rationales for this study are as follows:

- This group not classified as a category in which the giftedness must be revealed (there is no official recognition of their giftedness by not including the official definition of them and the absence of their own detection scale).

- A paucity of information about how inattention, hyperactivity, or impulsivity differ in the gifted group, including the non-gifted children with the disorder, gifted children without the disorder, and non-gifted children without the disorder.

- The absence of a detection scale to detect gifted students in this category in the Kingdom of Saudi Arabia.

\subsection{Study Objectives}

The study aims to:
- Investigating the differences between gifted and non-gifted students with ADHD in terms of characteristics and behaviors.

- Investigating the possibility of using the Overexcitability Scale to detect giftedness in the students with attention deficit hyperactivity disorder.

- Disclosure of the distinguishing features in terms of the type of Overexcitability among the gifted students with attention deficit hyperactivity disorder.

\subsection{Research Questions}

Question 1: What are the characteristics of attention disorder accompanied by hyperactivity in gifted students?

Question 2: Are there differences in the patterns of Overexcitability between gifted people with attention deficit hyperactivity disorder and others with the same disorder and not gifted?

Question 3: Is there a correlation between performance on the Overexcitability scale and the degree of intelligence of both gifted students who have the disorder and others?

\section{Research Methodology}

Comparative descriptive qualitative method

7.1 Review of previous studies.

7.2 Conducting the Overexcitability scale on the sample groups.

\subsection{Review of Previous Studies}

A search on previous research was made to answer the following question: What are the characteristics of attention disorder accompanied by hyperactivity in gifted students?

\subsection{The strategy used to search for previous studies}

Criteria for selecting studies

- Studies examined the same problem as the study, which is investigating the characteristics of gifted students with ADHD.

- Studies and research published between 1990 and 2019.

- Studies and research wrote in Arabic or English.

- Studies and research published in refereed journals.

Exclusion criteria:

- Articles published on websites. 
- The research focused on the study of ADHD only.

- The research focused on gifted individuals only.

\subsection{The strategy used in creating the studies}

Search words:

- Gifted students with hyperactivity and attention deficit hyperactivity disorder.

- Twice or Multi-Exceptional gifted students with attention deficit hyperactivity disorder.

- Gifted children with ADHD.

\subsection{Most important collected studies}

James and Diane [9] referred to the characteristics of gifted students with ADHD. The study diagnosed the disorder with several features, including the child's handwriting method, the bad spelling of letters, the sitting and fidgeting in class. She also discussed the possibility that some of these students were gifted, and these students were diagnosed with artistic giftedness. They found that these gifted students act as a positive model when they demonstrate their giftedness.

The study of "Deborah" [5] was distinguished from previous studies by its emphasis on the importance of a good diagnosis of attention deficit disorder accompanied by hyperactivity among gifted students in Connecticut. The study emphasized the importance of providing each student of this category with an appropriate education according to the educational goals. The results indicated that students of this group have 6 out of 8 necessary characteristics for diagnosing the disorder, with the importance of examining their competence and adaptation to the disorder. It also found appropriate results and an improved educational level for gifted students with attention deficit hyperactivity disorder.

Newcorn and Halperin [3] study of these groups during adolescence showed that the same symptom rates were consistent in gifted and non-gifted groups with the disorder. The study also compared groups of gifted, non-disordered adults with gifted adults with ADHD. The gifted with ADHD group reported lower quality of life, lower job performance, lower family and occupational performance, and more comorbidities. Based on the results of this study, the authors conclude that those with high IQ concurrent with ADHD (including children) show characteristics consistent with the diagnosis of ADHD individuals with average IQ (including children) and that the diagnosis of ADHD is true among individuals with high IQs (including children). However, since these studies did not include average IQ or markers of ADHD, these results need to be scrutinized before they are considered.

The Neihart study [10] examined the characteristics of gifted people with attention deficit hyperactivity disorder. The results indicated that many gifted people with attention disorder have a high level of social and emotional maturity.

Ancell et al.'s first [3] study compared groups of gifted non-disordered, and gifted children with ADHD. They found that gifted children with ADHD had: (1) higher rates of familial disorder among first-degree relatives, (2) a higher need for academic support, (3) higherlevel mental illness, and (4) poor performance on the "Wechsler cube design test for children's intelligence" (5) and more functional defects.

In Arffa [11] study gifted children with ADHD ( $\mathrm{n}=45$ ) showed a superior ability to shift focus, avoid mistakes, plan and organize. The performance scores on the tasks which are unrelated to executive functions were more than the average (such as decorate notebooks).

Tordjman study [12] which focused on the characteristics of gifted children with attention disorder accompanied by hyperactivity, through their exposure to behavioural treatments so that they can avoid school problems and depressive symptoms.

In Brown et al [4] study it was found that some people with high IQ can suffer from ADHD, while they show average results, but they have difficulty achieving the expected high level of their intelligence.

In Cordeiro et al [13] study of 275 Brazilian children having behavioural or learning difficulties. Fifteen children scored an IQ greater than 120, 10 of them had ADHD. The majority of these gifted children with ADHD showed problems with reading, math, or writing. They also suffered from a variety of coexisting disorders, including mood disorders, social problems, disruptive behaviours, and attention problems.

In a study Zentall, and Gentry [6] of gifted children attending a gifted summer camp. A comparison of working memory and creativity was made between those with and without ADHD symptoms. Gifted children with ADHD symptoms $(\mathrm{n}=17)$ had lower working memory, but higher creativity scores than gifted children without ADHD symptoms $(\mathrm{n}=20)$.

In a systematic review by Romelis et al. [14] it was found that with a high degree of intelligence, intentional behaviours appear, but not hyperactivity or impulsivity. Also, there are clinical features comparable to ADHD.

In the Fugate and Gentry [15] study, gifted girls with ADHD were different from their average ADHD peers. They were aware that their ability alone was not enough to achieve success. They knew the value of hard work and flexibility but there were some moments of frustration, and they also found it difficult to use the motivation and the effort. Perfect inclinations were also an issue. However, Using sports and creative activities was a good strategies for selfregulation for these girls.

The El-Nubi [16] study aimed to design a scale for diagnosing attention deficit hyperactivity disorder in 
gifted children, as well as ensuring the presence of gifted children with attention deficit hyperactivity disorder. The sample consisted of (52) gifted boys and girls with attention deficit hyperactivity disorder, whose ages ranged between (4-6) years, and the scale was effective in diagnosing attention deficit hyperactivity disorder among gifted children.

In Comes [2] study, the results indicate that (1) the diagnosis of ADHD is correct among gifted children, (2) gifted children may be less interested than children with non-gifted ADHD, and (3) it appears that Gifted children with ADHD differ from non-gifted children with ADHD with respect to behaviours described as hyperactive and impulsive "specific behaviours in hyperactive or impulsive behaviours".

\subsection{What are the characteristics of attention disorder accompanied by hyperactivity in gifted students?}

To answer the first question, the researcher found a set of characteristics that distinguish gifted students with attention deficit hyperactivity disorder, as follows:

\subsection{Academic characteristics}

- The way the child's handwriting and spelling are poor.

- Most of their giftedness is artistic.

- Adequate education for this group increases their competence and adaptability to the disorder.

- $\quad$ They need more academic support.

- They have lower working memory but higher creativity than gifted unaffected students.

\subsection{Social and emotional characteristics}

- High level of mental illness.

- Poor performance on the Wechsler scale cube division test.

- They have a higher level of emotional and emotional maturity than other sufferers.

- High rates of attention deficit hyperactivity disorder among first-degree relatives.

- Disturbances in coexistence (mood disruptive behavior - opposition).

\subsection{Behavioral characteristics}

- $\quad$ Fidgeting while sitting on a study bench.

- They have a positive attitude when paying attention to their giftedness.

- They have more functional flaws.

- Girls tend to talk excessively (gossip), and boys tend to move and be more aggressive.
- Superior ability to shift focus, avoid mistakes, plan and organize.

- Their performance on tasks unrelated to executive functions is above average.

- Behavioral treatments are effective in solving academic problems and depressive symptoms.

\subsection{Method for implementing the overexcitability scale}

The "Al Asalib Al Hadithat" school contributed to the current study sample of students with ADHD. Specifications of the sample were showed for the specialist's teacher in the school, and after reviewing the student's files, the researcher was provided with the data of the first category, which consists of 4 gifted students, whose intelligence scores were greater than 130 on the Binet scale, and their ages ranged from (710) years, and they were diagnosed with the disorder from a medical clinic using a scale Vanderelm. The data of the second category was also provided, which numbered 6 students with the disorder, whose intelligence degree was normal, and the IQ score was less than 120. From "the fourth secondary school in Al-Khobar", cooperation with the student counsellor was made to select the third category that contains 16 gifted students with "Miqias Mawhiba" classification. Finally, the fourth category was 10 average students in academic achievement. They were selected for the control sample through the nomination of teachers.

- The school's approval was obtained, which in turn obtained the parents' approval.

- A measure of the overexcitability scale of the four groups in the group was conducted.

- The files of the students of the Psychological Counselor at "Al Asalib Al Hadithat" School were used.

\subsection{Procedures for implementing the Overexcitability scale}

The sample has 4 categories:

- 4 gifted students (high intelligence) with ADHD.

- 6 students (average intelligence) with ADHD.

- 10 normal students

- 16 gifted students.

A verbal explanation was given to the gifted and normal students about the overexcitability scale (number $=26$ ). They were told that the purposes of the study were to explore the relationships between giftedness and the intensity of the overexcitability they have. The classroom teachers and the psychologists of the students were also interviewed with the student's achievement files. 


\section{Results}

The study aimed to identify the possibility of using the "Overexcitability Scale" as a giftedness detection tool for individuals who have attention deficit hyperactivity disorder. To collect the necessary data to answer the second and third question, the researcher used a scale of arousal patterns prepared by Falk, Linda, Miller, Begovsky and Silverman, and expressed by Al-Mutairi. Likert pentagram (applies to me highly, applies to me very much, applies to me to some extent, does not apply to me very much) The results of the study were obtained and presented sequentially according to the questions as follows:

\subsection{First: The results related to the second question}

The text of the question was "Are there differences in the Overexcitability Scale between gifted students with ADHD and others with the same disorder and non-gifted?"

To answer this question, the means and standard deviations of the Overexcitability Scale of both gifted and non-gifted students were extracted, and the Table 1 below illustrates this.

Table 1 . The results related to the second question

\begin{tabular}{|c|c|c|c|c|}
\hline \multicolumn{4}{|c|}{$\begin{array}{l}\text { Study Categories } \\
\end{array}$} & \multirow{3}{*}{$\begin{array}{c}\text { Overexci } \\
\text { abilities }\end{array}$} \\
\hline \multicolumn{2}{|c|}{$\begin{array}{c}\text { Non-gifted } \\
\text { students with } \\
\text { ADHD } \\
\end{array}$} & \multicolumn{2}{|c|}{$\begin{array}{c}\text { Gifted students with } \\
\text { ADHD }\end{array}$} & \\
\hline SD & Mean & SD & Mean & \\
\hline 0.397 & 2.950 & 0.622 & 4.225 & $\begin{array}{l}\text { Psychomot } \\
\text { or }\end{array}$ \\
\hline 0.375 & 2.767 & 0.630 & 4.275 & Sensual \\
\hline 0.407 & 2.800 & 0.781 & 2.80 & $\begin{array}{l}\text { Imaginatio } \\
\text { nal }\end{array}$ \\
\hline 0.449 & 2.050 & 0.565 & 4.475 & Intellectual \\
\hline 0.381 & 2.983 & 0.723 & 2.951 & Emotional \\
\hline
\end{tabular}

The Table 1 shows that the Mean and standard deviations of students with high intelligence with the disorder ranged between $(4.475-2.80)$. Where "Intellectual overexcitability" came in the first place with the highest mean (4.475). While the "Imaginational overexcitability" came in the last place with a mean of (2.80). The statistical analysis also indicates that the sample has a high overexcitability, respectively, in both Intellectual - Sensual Psychomotor. The results also showed that gifted students with ADHD have an excessive overexcitability higher than the average in the patterns of giftedness developed by Boschsky (1998). The results agree with the studies of Thamer Al-Mutairi [17] and the study of Jarwan [18]. This indicates that the overexcitability scale is a giftedness detector for this category. However, it ranged between (2.98 2.05) for the normal students, where the "Intellectual overexcitability" came in the last place with a mean of 2.05 .

\subsection{Second: The results related to the third question and its answer}

The text of the third question was, "Is there a correlation between performance on the Overexcitability scale and the degree of intelligence of both gifted students who have the disorder and others?"

To answer this question, the mean and standard deviations of the overexcitability of the four sample categories were extracted, and the Table 2 below illustrates them.

The results show that the mean of students with high intelligence with the disorder is higher than others. It also indicates that they are higher than average on Overexcitabilities. The result shows that it happens also in gifted students, but the difference between them was in the mean value and in the order of Overexcitabilities.

The Overexcitabilities in the gifted with the disorder category came in the order of (Intellectual Sensual - Psychomotor) and in the unaffected gifted (Imaginational - Psychomotor - Emotional), while the mean values of the normal student with the disorder and the unaffected student categories are close.

The results can indicate that there is a differential validity of the four groups and therefore the results can claim that the use of the Overexcitabilities Scale to detect the giftedness of children with the disorder was valid and it gives significant results.

\section{Study limitations}

The study achieved the results of the questions that were set, but the following restrictions must be observed:

First: The sample size that was obtained from gifted affected and gifted unaffected students is very small, and no statistical analysis was done to test the efficiency of the sample to justify the possibility of considering these results as significant or not.

Second: The gender in the four categories of the sample was not controlled and its effect was not measured. As the group of the sample affected by the disorder was male and the group of the control sample and the gifted unaffected sample were females.

Third: The definition of giftedness in the sample categories is different. As the high intelligence index on the Binet scale was considered for the affected 
Table 2. The results related to the third question

\begin{tabular}{|c|c|c|c|c|c|c|c|c|}
\hline \multicolumn{8}{|c|}{ Study Categories } & \multirow{3}{*}{ Overexcitabilities } \\
\hline \multicolumn{2}{|c|}{ Normal Students } & \multicolumn{2}{|c|}{ Gifted students } & \multicolumn{2}{|c|}{$\begin{array}{l}\text { Non-gifted } \\
\text { students with } \\
\text { ADHD }\end{array}$} & \multicolumn{2}{|c|}{$\begin{array}{l}\text { Gifted students } \\
\text { with ADHD }\end{array}$} & \\
\hline SD & Mean & SD & Mean & SD & Mean & SD & Mean & \\
\hline 0.389 & 2.3431 & 0.512 & 3.522 & 0.397 & 2.950 & 0.622 & 4.225 & Psychomotor \\
\hline 0.375 & 2.501 & 0.300 & 3.285 & 0.375 & 2.767 & 0.630 & 4.275 & Sensual \\
\hline 0.408 & 2.483 & 0.521 & 3.781 & 0.407 & 2.800 & 0.781 & 2.80 & Imaginational \\
\hline 0.458 & 2.416 & 0.865 & 3.415 & 0.449 & 2.050 & 0.565 & 4.475 & Intellectual \\
\hline 0.372 & 2.436 & 0.563 & 3.45 & 0.381 & 2.983 & 0.723 & 2.951 & Emotional \\
\hline
\end{tabular}

sample group as a determinant of the gifted, while in the gifted unaffected category, a "Mqias Mawhiba" was considered, and the control sample was chosen as a control sample as a result of their average academic achievement and the nomination of Mathematics and Biology teachers.

\section{Conclusion}

The study tried to highlight the possibility of using the overexcitability Scale for gifted students who have attention disorder accompanied by yperactivity, according to several premises:

- Increasing the rates of gifted children with attention deficit hyperactivity disorder.

- Diversity of causes of attention deficit hyperactivity disorder in children.

- The importance of the accurate detection of gifted children with attention deficit hyperactivity disorder in revealing their giftedness or diagnosing the severity of their disorder.

This study provides an entry point for future studies on gifted children who have attention deficit hyperactivity disorder It draws the attention of educational officials by studying the strengths of students who have disorders.

\section{References}

[1] Mullet, D. R., \& Rinn, A. N. (2015). Giftedness and ADHD: Identification, misdiagnosis, and dual diagnosis. Roeper Review, 37(4), 195-207. (Access Date: 6 May, 2020).

[2] Gomez, R., Stavropoulos, V., Vance, A., \& Griffiths, M. D. (2019). Gifted Children with ADHD: How Are They Different from Non-gifted Children with ADHD? International Journal of Mental Health and Addiction, 115.(Access Date: 12 June, 2020).
[3] Newcorn, J. H., Halperin. (2001). Symptom profiles in children with ADHD: effects of comorbidity and gender. Journal of the American Academy of Child \& Adolescent Psychiatry, 40(2), 137-146. (Access Date: 20 June, 2020).

[4] Brown, T. E., Reichel, P. C., \& Quinlan, D. M. (2011). Executive function impairments in high IQ children and adolescents with ADHD. Open Journal of Psychiatry, 1, 5665. (Access Date: 20 May, 2020).

[5] Deborah LaPlace (1999): Research into ADD/ADHD and Gifted Identification and Education, developed within EDU 577 - International and Cross-Cultural Education, Online CSU, ERIC Clearinghouse on Handicapped and Gifted Children, Reston,Va. (Access Date: 13 May, 2020).

[6] Guettal, Zoe\& Potter, Tom (2000): Social Skills Development in Deficit/Hyperactivity Disorder through Participation in a Residential: Children with Attention Pathways: The Ontario Journal of Outdoor Education; V(12), N.(5), P.P. (9-11). (Access Date: 10 June, 2020).

[7]. Antshel, K. M., Faraone, S. V., Stallone, K., Nave, A., Kaufmann, F. A., Doyle, A., Biederman, J. (2007). Is attention deficit disorder a valid diagnosis in the presence of high IQ? Results from the MGH Longitudinal Family Studies of ADHD. Journal of Child Psychology and Psychiatry, 48, 687-694. (Access Date: 5 May, 2020).

[8] Al-Jughayman, Abdullah (2019). A practical guide for psychologically and academically gifted students. Hamdan Bin Rashid Al Maktoum Foundation. (Access Date: 13 June, 2020).

[9] James T. Webb \& Diane Latimer(1993): ADHD and Children Who Are Gifted, The Council for Exceptional Children, ERIC Clearinghouse on Disabilities and Gifted Children, Reston, Va., School of Professional Psychology, Wright State University, Dayton, Ohio. (Access Date: 7 May, 2020).

[10] Neihart, Maureen (2003): Gifted children with Attention Deficit Hyperactivity Disorder (ADHD)., Clearinghouse on Disabilities and Gifted Education, Disabilities and Gifted ,Education, Arlington, VA (Access Date: 10 June, 2020). 
[11] Arffa, S. (2007). The relationship of intelligence to executive function and non-executive function measures in a sample of average, above average, and gifted youth. Archives of clinical neuropsychology, 22(8), 969978. (Access Date: 6 June, 2020).

[12] Tudjman, S. (2006). Gifted children in difficulty: from attention deficit hyperactivity disorder to depression and school failure. Revue medical Suisse, 2(54), 533-4. (Access Date: 26 May, 2020).

[13] Cordeiro, M. L., Farias, A. C., Cunha, A., Benko, C. R., Farias, L. G., Costa, M. T., ... \& McCracken, J. T. (2011). Co-occurrence of ADHD and high IQ: a case series empirical study. Journal of attention disorders, 15(6), 485490. (Access Date: 18 June, 2020).

[14] Rommelse, N., Langerak, I., van der Meer, J., de Bruijn, Y., Staal, W., Oerlemans, A., \& Buitelaar, J. (2015). Intelligence may moderate the cognitive profile of patients with ASD. PLoS One, 10(10), e0138698. (Access Date: 2 May, 2020).

[15] Fugate, C. M., \& Gentry, M. (2016). Understanding adolescent gifted girls with ADHD: Motivated and achieving. High Ability Studies, 27(1), 83-109. (Access Date: 18 May, 2020).

[16] El-Noubi, Mohamed (2018). Diagnosis of Attention Deficit Hyperactivity Disorder in Gifted Children (4-6) Years. International Journal of Arts and Humanities. (Access Date: 2 June, 2020).

[17] Al-Mutairi, T, \& Jarwan, F. (2008). The relationship between the patterns of super-excitability according to Dabrowsky's theory and between intelligence and academic achievement and its effectiveness in detecting gifted students in the middle school in Kuwait. Amman Arab University, Amman. Retrieved from http://search.manduma h.com/Record/635132. (Access Date: 4 June, 2020).

[18] Jarwan, F. (2011). The effectiveness of the superexcitability scale in detecting academically gifted students. Educational Sciences: Cairo University - Faculty of Graduate Studies of Education, Vol. 19, p. 3, 161-184. Retrieved from http://search.mandumah.com/Record/11509 0. (Access Date: 28 May, 2020). 